\title{
Determination of thermal stratification and its effects on water quality in dams using analytical methods
}

\author{
G. Badalians Gholikandi ${ }^{1}$, E. Jalilzadeh ${ }^{2}$, H. R. Orumieh ${ }^{3}$ \\ \& H. R. Tashaouie ${ }^{4}$ \\ ${ }^{I}$ Power and Water University of Technology (PWUT), \\ Water Research Institute (WRI), Iran \\ ${ }^{2}$ Tehran Water and Wastewater Company (TWWC), Iran \\ ${ }^{3}$ Parsarianab Consulting Engineers, Iran \\ ${ }^{4}$ National Water and Wastewater Company (NWWC), Iran
}

\begin{abstract}
Data analysis should be viewed as an integral component of the water quality management process [1]. Statistical techniques such as factor analysis (FA), cluster analysis (CA) and $\mathrm{T}$ test were applied to get information about the similarities or dissimilarities, to detect thermal stratification and to interpret Amir Kabir Dam water quality data. Analyses were based on 150 total samples from 5 depths during about a two year period (from April 2008 to April 2010) which were measured for 29 (19 physicochemical and 10 biological) parameters resulting in 4350 observations. Using PCA/FA for physicochemical variables, five Varifactors were obtained with eigenvalues $>1$ contributing to almost $82.342 \%$ of total variance in water dataset which are included on the components. Moreover, FA is a helpful method for physicochemical data reduction, although it is not as good for biological data reduction. Thermal stratification is the biggest problem at the majority of deep reservoirs resulting from the surface warming. It results in water quality detritions in the bottom layers. Finding the depths affected by this occurrence is an important problem in the management of reservoirs. In this study CA and t-test were applied to identify thermal stratification and its consequences on water quality. Sampling stations were grouped into two main classes using CA during each season. After $\mathrm{CA}, \mathrm{T}$ test was applied to detect the statistical importance of differences between
\end{abstract}


clusters. 0 and 10 depths differ from lower depths during spring and summer. These layers contain more physicochemical and less biological parameters compared to lower depths. This study revealed the effectiveness of CA and T test for thermal stratification detection, which provides some important benefits including enhanced water quality management, greater confidence in water treatment processes, and improved efficiency in reservoir management.

Keywords: water quality, thermal stratification, statistical techniques $F A / C A / T$ test, Amir Kabir Dam.

\section{Introduction}

Dams are essential for an arid country, like Iran, to supply water requirements. Seasonal variations in precipitation, surface runoff, agricultural, municipal and industrial wastewaters, and groundwater flow and pumped in and out flows and air temperature have a strong effect on dams' water quality and quantity. These resources of water have many important uses such as for drinking, recreational and industrial uses, fish and wildlife, and irrigation. Amir Kabir Dam has been constructed primarily for drinking water supply system of Tehran. Water quality obviously plays a critical role in all aspects. Degradation of dam water quality can considerably limit its usages; therefore, monitoring and controlling water quality is necessary for protection of water resources and has received special attention accordingly. To assess water environment quality, obtaining its parameter data is indispensable. One management method that is specific to drinking water reservoirs is the selection of the best water layer from which water is withdrawn for treatment. One of the most important problems related to water quality in dams, especially during warm seasons, is thermal stratification.

Dealing with stratification within water supply reservoirs is a common problem for urban water authorities. Failure to identify and control stratification can compromise water treatment operations, meeting regulatory standards, customer expectations, environmental flow releases and potentially isolate an affected reservoir from a supply system. Without intervention, the severity of stratification commonly increases, along with the possibility of drawing poor quality water from a storage reservoir. Hence, water treatment processes and water resource operation can potentially become complicated and difficult to manage [2]. Reservoir management of the source system can be a very affective first step in water treatment. Although the regular measurements need much work, it is necessary to provide a representative and reliable estimation of surface water quality because of spatial and temporal variation of water environment quality. The long-term monitoring for many profiles in different reach will generate a large and complex database [3]. A particular problem in the case of water quality monitoring is the complexity associated with analyzing the large number of measured variables. The data sets contain rich information about the behavior of the water resources. Classification, modeling and interpretation of monitored data are the most important steps in the assessment of water quality [4]. The best approach to avoid misinterpretation of environmental monitoring data is the application of multivariate statistical methods for environmental data 
classification and modeling [5]. Multivariate statistical analysis offers a powerful means for identifying similarities among the variables present in the chemical composition of water [6]. The goal of such a statistical interpretation of the data is to make some assumptions on observed variations in the data and biogeochemical processes controlling the changes in element concentrations, thus raising the knowledge on the environmental behavior of different elements. It should be noted, however, that interpretation of a large volume of the experimental results may present certain problems [7]. Different multivariate statistical techniques have been widely used to evaluate surface waters. These techniques have been applied in the management of Nakdong River Watershed [8]. Sojka et al. [9], Venugopal et al. [10], Varol and Sen [11], Zhang et al. [12], and Wang et al. [13] applied these techniques in the assessment and identification of pollution sources in various surface waters.

The most common methods used in these studies are cluster analysis (CA), discriminant analysis (DA), factor analysis (FA), principal component analysis (PCA), and exploratory factor analysis (EFA). The CA technique is an unsupervised classification procedure that involves measuring either the distance or the similarity between the objects to be clustered. The resulting clusters of objects should then exhibit high internal (within cluster) homogeneity and high external (between clusters) heterogeneity [14]. Factor analysis is a multivariate analytical technique, which derives a subset of uncorrelated variables called factors explaining the variance observed in the original dataset. Factor analysis is used to uncover the latent structure of a set of variables [15]. Although, analytical techniques have been most applied for rivers water quality assessment but they were rarely used for dams'. In the present study two of these techniques, CA and PCA/FA, were applied to assess water quality for better management of Karaj Dam. T test is applied to complete CA results interpretation.

\section{Materials and methods}

Water quality data were derived from the monitoring program of Karaj Dam administered by Tehran Water and Wastewater Company during a two year period (from April 2008 to April 2010). Samples were collected from five depths of the dam on a monthly basis. Twenty nine parameters were measured for 150 selected samples ultimately leading to 4350 observations which were afterwards subjected to different univariate and multivariate techniques such as $\mathrm{T}$ test, factor analysis and cluster analysis. The measured physico-chemical and biological parameters are: temperature $\mathrm{T}^{\circ}$, turbidity, calcium $\mathrm{Ca}^{2+}$, magnesium $\mathrm{Mg}^{2+}$, sodium $\mathrm{Na}$, potassium $\mathrm{K}^{+}$, total hardness $\mathrm{TH}$, phenol-phetalein alkalinity $\mathrm{PA}$, total alkalinity TA, $\mathrm{pH}$, phosphate $\mathrm{PO}_{4}{ }^{3-}$, sulfate $\mathrm{SO}_{4}{ }^{2-}$, silicate $\mathrm{SiO}_{2}{ }^{-}$, ammoniac $\mathrm{NH}_{3}$, nitrite $\mathrm{NO}_{2}^{-}$, nitrate $\mathrm{NO}_{3}^{-}$, chloride $\mathrm{Cl}^{-}$, total dissolved solids TDS, conductivity EC, total coliform TF, fecal coliform FC, diatomea, chlorophycea, cianoficea, protozoa, rotifer, crustacean and other Organisms. Table 1 presents the basic statistics of the dataset. Data treatment with multivariate analytical techniques, FA and $\mathrm{CA}$ and $\mathrm{T}$ test was carried out to determine depths with similar water quality, spatial variation of water quality, main variables resulting 
differences between depths and the ability of multivariate analytical techniques for data reduction. To carry out mathematical and statistical computations, Microsoft Office Excel 2007 and SPSS 15 software packages were employed.

Table 1: $\quad$ Descriptive statistics for the water quality data used for this study.

\begin{tabular}{|c|c|c|c|c|c|c|c|}
\hline Parameter & unit & Min & Mean & Max & StDev & Skewness & Kurtosis \\
\hline Tcoli & $/ 100 \mathrm{ml}$ & 1 & 19.33 & 350 & 42.74 & 4.91 & 29.59 \\
\hline Fcoli & $/ 100 \mathrm{ml}$ & 1 & 4.19 & 49 & 7.64 & 4.11 & 18.90 \\
\hline diatomea & $/ 100 \mathrm{ml}$ & 21888 & 332861.61 & 2012160 & 350485.01 & 2.75 & 9.54 \\
\hline chlorophycea & $/ 100 \mathrm{ml}$ & 24 & 3836.97 & 47104 & 6405.60 & 3.41 & 15.80 \\
\hline cianoficea & $/ 100 \mathrm{ml}$ & 0 & 0.83 & 12 & 1.89 & 2.97 & 10.91 \\
\hline protozoa & $/ 100 \mathrm{ml}$ & 0 & 423.20 & 6912 & 1108.77 & 4.50 & 20.08 \\
\hline rotifer & $/ 100 \mathrm{ml}$ & 0 & 3.65 & 28 & 4.30 & 2.28 & 7.94 \\
\hline crustacea & $/ 100 \mathrm{ml}$ & 0 & 3.74 & 16 & 3.36 & 1.30 & 2.35 \\
\hline Nematod & $/ 100 \mathrm{ml}$ & 0 & 0.34 & 4 & 0.85 & 2.56 & 6.17 \\
\hline others & $/ 100 \mathrm{ml}$ & 0 & 0.05 & 3 & 0.38 & 7.20 & 51.61 \\
\hline temperature & ${ }^{\circ} \mathrm{C}$ & 5 & 11.20 & 24 & 4.33 & 0.54 & -0.25 \\
\hline EC & $\mu \mathrm{S} / \mathrm{cm}$ & 218 & 326.42 & 393 & 33.26 & 0.08 & 0.24 \\
\hline pH & & 7.63 & 8.14 & 8.79 & 0.20 & 0.03 & 0.59 \\
\hline Turbidity & NTU & 0.8 & 3.06 & 9.3 & 1.95 & 1.30 & 1.24 \\
\hline TDS & $\mathrm{mg} / \mathrm{L}$ & 128 & 209.62 & 2016 & 150.32 & 11.88 & 143.68 \\
\hline PA & $\begin{array}{l}\mathrm{mg} / \mathrm{L}- \\
\mathrm{CaCO}_{3}\end{array}$ & 0 & 0.52 & 8 & 1.39 & 3.07 & 9.57 \\
\hline TA & $\begin{array}{l}\mathrm{mg} / \mathrm{L}- \\
\mathrm{CaCO}_{3}\end{array}$ & 64 & 109.09 & 124 & 8.66 & -1.98 & 6.88 \\
\hline ТH & $\begin{array}{l}\mathrm{mg} / \mathrm{L}- \\
\mathrm{CaCO}_{3}\end{array}$ & 84 & 141.93 & 172 & 14.18 & -0.29 & 1.45 \\
\hline $\mathrm{Ca}^{2+}$ & $\mathrm{mg} / \mathrm{L}$ & 24 & 45.15 & 143.2 & 9.91 & 6.42 & 64.78 \\
\hline $\mathrm{Mg}^{2+}$ & $\mathrm{mg} / \mathrm{L}$ & 4 & 7.64 & 12.48 & 1.55 & -0.15 & -0.12 \\
\hline $\mathrm{Na}^{+}$ & $\mathrm{mg} / \mathrm{L}$ & 7 & 13.48 & 21 & 2.94 & 0.42 & 0.15 \\
\hline $\mathbf{K}+$ & $\mathrm{mg} / \mathrm{L}$ & 0.8 & 0.99 & 1 & 0.03 & -5.46 & 29.98 \\
\hline $\mathrm{Cl}^{-}$ & $\mathrm{mg} / \mathrm{L}$ & 5 & 9.49 & 16 & 2.13 & 0.19 & -0.21 \\
\hline $\mathrm{SO}_{4}{ }^{2-}$ & $\mathrm{mg} / \mathrm{L}$ & 30 & 45.36 & 60 & 8.14 & 0.01 & -0.99 \\
\hline $\mathrm{SiO}_{2}^{-}$ & $\mathrm{mg} / \mathrm{L}$ & 0 & 6.95 & 11 & 1.94 & -1.00 & 1.68 \\
\hline $\mathrm{NH}_{3}$ & $\mathrm{mg} / \mathrm{L}$ & 0 & 0.16 & 2.6 & 0.39 & 4.89 & 23.76 \\
\hline $\mathrm{NO}_{3}^{-}$ & $\mathrm{mg} / \mathrm{L}$ & 1 & 4.13 & 9 & 1.89 & 0.67 & -0.11 \\
\hline $\mathrm{NO}_{2}^{-}$ & $\mathrm{mg} / \mathrm{L}$ & 0 & 0.10 & 0.32 & 0.06 & 0.54 & 1.04 \\
\hline $\mathrm{PO}_{4}{ }^{3-}$ & $\mathrm{mg} / \mathrm{L}$ & 0.01 & 0.03 & 0.33 & 0.04 & 5.68 & 39.75 \\
\hline
\end{tabular}

\subsection{Amir Kabir Dam (Karaj Dam)}

Amir Kabir Dam (Karaj Dam), one of the most important water resources of Tehran province, has been constructed on Karaj River. Karaj River annual mean flow rate at its entrance to Karaj dam is $450 \times 106 \mathrm{~m}^{3}$; additionally 8.2 and 1450 $\mathrm{m}^{3} / \mathrm{s}$ in this location were measured, respectively as minimum and peak annual temporal flow rates. This dam supplies water for municipal and cultural uses and 
electrical energy generation. It has been located 23 kilometers north of Karaj and 63 kilometers northwest of Tehran, and is under operation since 1963. The total and useful volumes of Amir Kabir Dam are 202 and 191.6 MCM and its normal water depth is about 65 meters [16-19].

\section{Results and discussion}

\subsection{Factor analysis}

FA with principal component analysis extraction (PCA) method on the physicochemical data set resulted in five principal components (PCs) which after "Varimax rotation method with Kaiser Normalization" gave rise to six varifactors (VFs) with Eigenvalues $>1$. In general, the higher the eigenvalue is, the more significant the corresponding component is. Rotating the axis extracts a new group of variables known as Varifactors. In contrast to PCs that are linear combinations of observed variables, VFs include unobserved, hypothetical, latent water quality variables [20]. VFs and PCs have the same variations. In PCA communalities represent the proportion of the variance in the original variables that is accounted for by the factor solution. The factor solution should explain at least half of each original variable's variance, so the communality value for each variable should be 0.50 or higher. On iteration 1 , the communalities for the variables $\mathrm{PO}_{4}$, TDS, turbidity and $\mathrm{Ca}$ were $0.134,0.258,0.430$ and 0.484 , respectively. Then it is necessary to remove these variables because of their low communality values. On the next iteration the communality for all remained variables was greater than 0.5 . The information in the remained variables can be represented by 5 components or varifactors. These varifactors explain $82.342 \%$ of the total variance; Out of the $82.342 \%$ of total variation, however, VF1, VF2, VF3, VF4 and VF5 explain 29.750\%, 19.698\%, 15.137\%, 10.545\% and 7.213\%, respectively. Table 2 summarizes VFs and loading of parameters. Many studies have classified VFs into three groups: $0.3-0.5$ as weak, $0.5-0.75$ as moderate and $>0.75$ as strong [9]. On the basis of this classification, VF1 (hardness and dissolved solids factor) has significant positive loading on $\mathrm{TH}, \mathrm{EC}, \mathrm{SO}_{4}, \mathrm{~T}, \mathrm{TA}$ and $\mathrm{Cl}$ indicates the contribution of natural sources e.g. soil erosion. A negative correlation with $\mathrm{T}$ reflects the influence of temperature on dissolved solids solubility; higher water temperature leads to lower solubility of hardness agents. $\mathrm{K}, \mathrm{NH}_{3}$ and $\mathrm{NO}_{3}$ rooting from point and non-point source pollutions such as agricultural and municipal activities have been loaded on VF2 (nutrient factor). VF3 (carbonate alkalinity factor), loaded on $\mathrm{pH}$ and PA represents leaching of carbonate compounds out of soil. VF4 revealed positive significant loading on $\mathrm{Mg}$ and $\mathrm{NO}_{2}$ and negative one on $\mathrm{Si}$.

These parameters can be originated from anthropogenic or natural pollution. The last VF, VF5 ( $\mathrm{Na}$ or salinity factor) involved $\mathrm{Na}$ from natural resources. There are 10 microbial and biological parameters FA could not have such good data reduction as for physicochemical parameters. In the first and second iterations cianoficea, protozoa, crustacean and others and Rotifer have community values lower 0.5 . 
Table 2: $\quad$ Loadings of variables on significant varifactors for the data set.

\begin{tabular}{|c|c|c|c|c|c|}
\hline & \multicolumn{5}{|c|}{ Component } \\
\hline $\mathrm{TH}$ & .955 & -.068 & -.061 & -.003 & -.084 \\
$\mathrm{EC}$ & .946 & -.097 & .001 & .053 & .107 \\
$\mathrm{SO}_{4}$ & .804 & .109 & .265 & .097 & .363 \\
$\mathrm{~T}$ & -.773 & -.308 & .121 & .078 & .368 \\
$\mathrm{TA}$ & .744 & -.186 & -.358 & -.245 & .039 \\
$\mathrm{Cl}$ & .737 & .125 & .311 & .233 & .398 \\
$\mathrm{NH}_{4}$ & -.101 & .859 & -.061 & -.141 & .259 \\
$\mathrm{NO}$ & .230 & .844 & -.112 & -.004 & -.140 \\
$\mathrm{~K}$ & .130 & -.832 & .057 & .166 & -.268 \\
$\mathrm{pH}$ & .163 & -.166 & .878 & -.169 & -.069 \\
$\mathrm{PA}$ & -.071 & -.081 & .860 & -.018 & .023 \\
$\mathrm{Mg}$ & .213 & -.044 & -.047 & .824 & -.100 \\
$\mathrm{NO}$ & -.083 & -.239 & -.121 & .780 & -.053 \\
$\mathrm{Si}$ & .226 & -.011 & -.399 & -.523 & -.140 \\
$\mathrm{Na}$ & .130 & .296 & -.065 & -.146 & .876 \\
\hline
\end{tabular}

The remained biological parameters comprise 3 varifactors which are responsible for $82.7 \%$ of total variance in the parameters which are included on these varifactors as shown in figure 1. In the factor analysis, loading of parameters on fewer varifactors which explaining the highest variation results in better data reduction. Parameters loaded on no VFs show any significant variation during sampling period and parameters loaded on the same VF have similar variation.

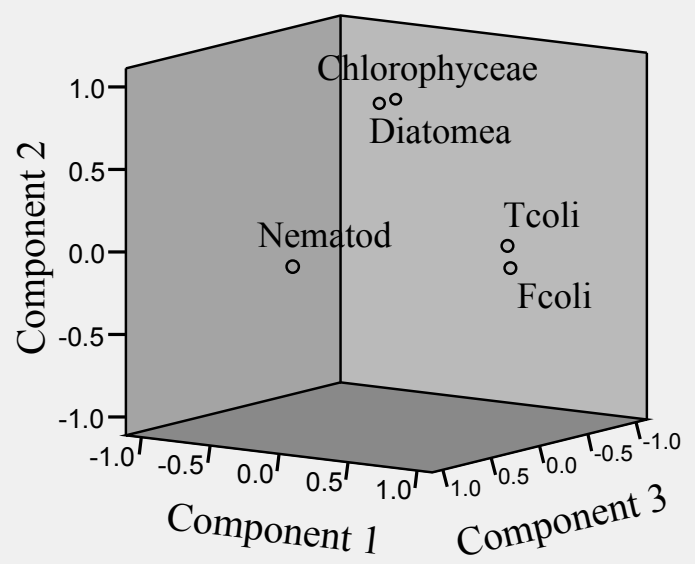

Figure 1: Component plot of Microbial parameters loading in rotated space. 


\subsection{Cluster analysis}

\subsubsection{Cluster analysis for detection of thermal stratification}

Thermal stratification occurs at a majority of deep reservoirs resulting from the surface warming. It stops mixing and prevents reaching oxygen to the bottom depths. These result water quality detritions in the bottom layers. Water intake point to comply best water quality for various usages is affected by thermal stratification. The prediction of this happening and the depths affected by it are important subjects in the management of water resources.

In this study the ability of analytical techniques has been studied to identify temperature stratification probability and to assess water quality along the depth of dam to propose the best water intake depth.

At first, cluster analysis grouped depths on the basis of water temperature similarity in each season, after that t-test examined statically significance between clusters. CA classified five depths into two main groups. In spring and summer, 0 and 10 meter depths have similar temperature and others are located in group 2.

In autumn, depths of 0,10 and 20 meters are grouped in a cluster and the remained depths fall into the other cluster while in winter just 50 meter depth has different temperature rather than the other ones. After clustering $T$ test applied to examine statically significance of average temperature differences between clusters; obtained $\mathrm{P}_{\text {values }}$ are $0.029,0.000, .663$ and .993 for spring, summer, autumn and winter, respectively. Considering $\mathrm{CA}$ and t-test results, temperature stratification occurs in spring and it accelerates during summer because of air temperature and depth of the dam. In cold season mixing occurs and water temperature in all depths is similar. Then thermocline layer is up to 10 meters and limits oxygen transferring to lower depths during spring and summer.

\subsubsection{CA for water quality determination in depths}

One of the most important subjects (problem) in water providing from dams is the water intake point to satisfy the best quality for aimed usage. Water should be at an intake from a depth to insure acceptable water quality and quantity. To determine suitable water intake depth it is necessary to know the water quality at all depths. Although classifying depths on the basis of water temperature is helping to identify water layers but it may not delineate water quality along with depths, so it should be done separately. Water quality parameters in this study include 19 physicochemical parameters and 10 microbial and biological parameters. Due to probable different behavior of two groups, CA was done on each group separately.

Cluster Analysis grouped depths in two main clusters according to physicochemical water quality in each season. In spring 0 and 10 meter depths are similar from this point of view and the others locate in cluster two. In summer physicochemical parameters in surface layer (0 meter depth) are different from those of other depths. In autumn lower layers (40 and 50 meters) have different quality rather than higher depths and ultimately in winter all of 
depths but 50 meter depth are in the same cluster. Differences between groups are just statically significant in spring and summer $\left(\mathrm{P}_{\text {value }}<0.05\right)$.

Biological water quality of Amir Kabir Dam classifies depths in all seasons in two groups. In spring and summer that difference between groups is important $\left(\mathrm{P}_{\text {value }}<0.05\right) 0$ and 10 meter depths (cluster one) have different quality of the remained ones. Differences between groups are resulted from higher amount of physicochemical and lower amount of biological parameters in the surface layers rather than those of lower layers. Reaction and precipitation may be the reason for decreasing of physicochemical variable along the depth but unavailability to oxygen for biological elements in lower layers limit the number of them in the bottom depths. Figure 2 shows depths classification on the basis of total available water quality parameters along with Amir Kabir Dam.

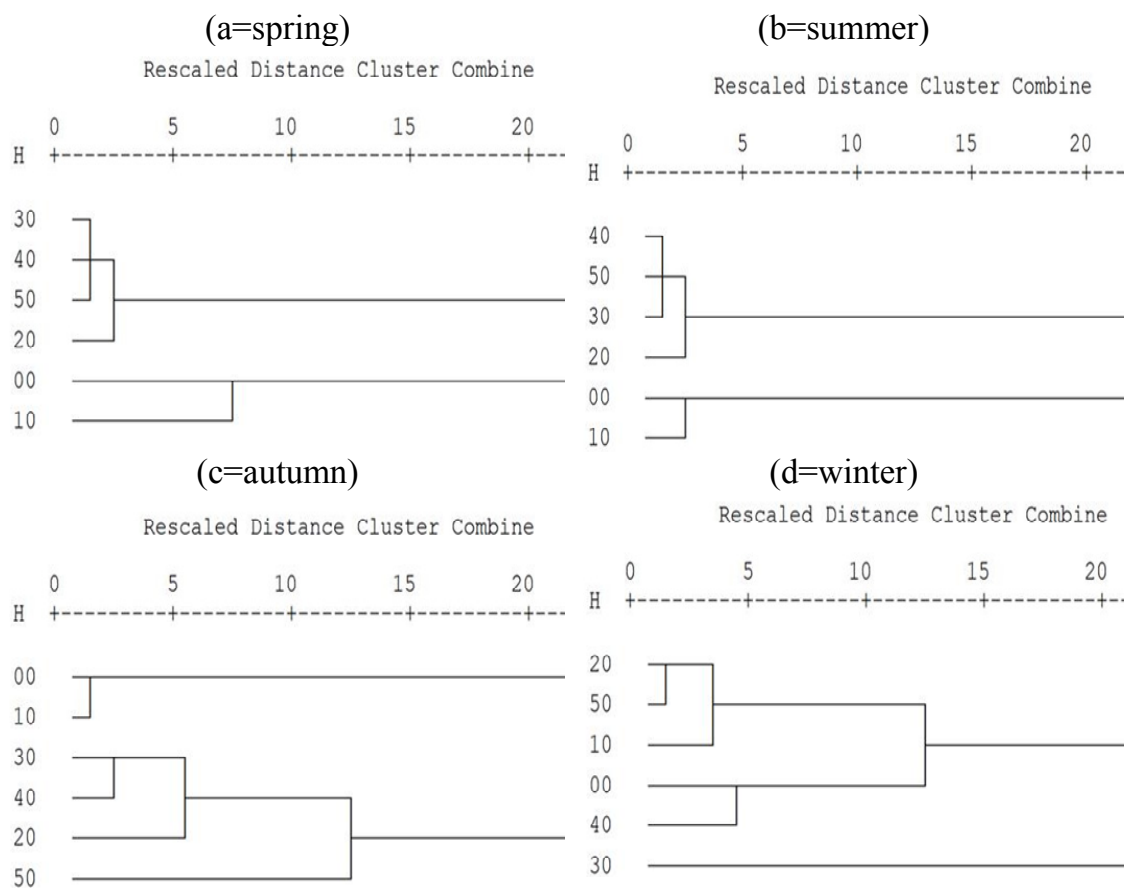

Figure 2: Dendrogram (using average linkage) showing clustering of monitoring depths on the Amir Kabir Dam during various seasons: a (spring), b (summer), c (autumn) and d (winter).

\section{Conclusion}

In the present study the effectiveness of statistical techniques in determining thermal stratification in a dam has been assessed. Multivariate and univariate techniques such as FA and CA and $\mathrm{T}$ test were conducted to determine most important variables on the water quality variation, group correlated variables, 
cluster similar sampling depths, and also assess water quality along with the dam. Both available natural and anthropogenic variables have significant variations on water quality. Putting out turbidity, TDS, $\mathrm{Ca}, \mathrm{PO}_{4}$, because of low community, out of 19 physicochemical parameters 3 anthropogenic pollutants include $20 \%$ of total variation in the variables which are included on the 5 varifactors. FA can be used in physicochemical data reduction rather than for biological parameters. Treatment of the data set by FA/PCA delineates effectiveness of this technique in reducing data during future sampling and consequence time and cost benefits. Employing FA for data reduction is useful for the water quality assessment and the management of surface waters as it groups 19 physicochemical parameters into 5 VFs contributing to $82.34 \%$ of the total variation. Moreover, it identifies those parameters or factors with the greatest effect on the temporal variation in Amir Kabir Dam water quality. Some of the measured parameters showed no variation during sampling period. CA accompanied with t-test can detect thermal stratification occurring in dams. This occurrence happens during spring and summer in Amir Kabir Dam. Also these methods are able to determine optimum water intake point in the view of each parameter. During temperature stratification unlike physicochemical parameters that are higher in surface layers, biological parameters decrease in lower layers due to lower available oxygen. Maintenance of suitable temperature and oxygen habitat conditions is important for raw water quality.

\section{References}

[1] Australian Guidelines for Water Quality Monitoring and Reporting, 2000... Chapter Six, Data Analysis and Interpretation.

[2] Perks, C. 2006. Dealing with stratification within a water supply reservoir, Bendigo. 69th Annual Water Industry Engineers and Operators Conference, 31-36.

[3] Zhang, Q., et al., 2009. Assessment of surface water quality using multivariate statistical techniques in red soil hilly region: a case study of Xiangjiang watershed, China. Environmental Monitoring and Assessment, 152(1-4), 123-131.

[4] Iscen, C.F., et al., 2008. Application of multivariate statistical techniques in the assessment of surface water quality in Uluabat Lake, Turkey. Environmental Monitoring and Assessment, 144(1-3), 269-276.

[5] Boyacioglu, H., Boyacioglu, H., 2008. Water pollution sources assessment by multivariate statistical methods in the Tahtali Basin, Turkey. Environmental Geology, 54(2), 275-282.

[6] Giridharan, L., Venugopal, T., Jayaprakash, M., 2009. Assessment of Water Quality Using Chemometric Tools: A Case Study of River Cooum, South India. Archives of Environmental Contamination and Toxicology, 56(4), 654-669.

[7] Shtangeeva, I., et al., 2009. Multivariate statistical analysis of nutrients and trace elements in plants and soil from northwestern Russia. Plant and Soil, 322(1-2), 219-228. 
[8] Han, S., Kim, E., Kim, S., 2009. The Water Quality Management in the Nakdong River Watershed using Multivariate Statistical Techniques. Ksce Journal of Civil Engineering, 13(2), 97-105.

[9] Sojka, M., et al., 2008. Application of multivariate statistical techniques to evaluation of water quality in the Mala Welna River (Western Poland). Environmental Monitoring and Assessment,147(1-3), 159-170.

[10] Venugopal, T., Giridharan, L., Jayaprakash, M., 2008. Groundwater quality assessment using chemometric analysis in the Adyar River, South India. Archives of Environmental Contamination and Toxicology, 55(2): p. 180190.

[11] Varol, M., Sen, B., 2009. Assessment of surface water quality using multivariate statistical techniques: a case study of Behrimaz Stream, Turkey. Environmental Monitoring and Assessment, 159(1-4), 543-553.

[12] Zhang, Y., et al., 2009. Water quality assessment and source identification of Daliao river basin using multivariate statistical methods. Environmental Monitoring and Assessment, 152(1-4), 105-121.

[13] Wang, X.L., et al., 2007. Multivariate analysis of interactions between phytoplankton biomass and environmental variables in Taihu lake, China. Environmental Monitoring and Assessment, 133(1-3), 243-253.

[14] Kazi, T.G., et al., 2009. Assessment of water quality of polluted lake using multivariate statistical techniques: A case study. Ecotoxicology and Environmental Safety, 72(2), 301-309.

[15] Yidana, S.M., Ophori, D., Banoeng-Yakubo, B., 2008. A multivariate statistical analysis of surface water chemistry data--The Ankobra Basin, Ghana. Journal of Environmental Management, 86(1), 80-87.

[16] Adib, A., Majd, A.R.M, 2009. Optimization of reservoir volume by yield model and simulation of it by dynamic programming and Markov chain method. American-Eurasian Journal of Agricultural and Environmental Science, 5(6), 796-803.

[17] Karaj-info, City of Karaj information network. http://www.karaj.info/nplaces.asp.

[18] Ehsan, G., 2008. Assessment of surface and groundwater resources in western area of Tehran province. International Journal of Applied Agricultural Research, 3(1), 75-84.

[19] Company, T.W.W., 2008-2010. Tehran Water \& Wastewater Company.

[20] Singh, K., et al., 2004. Multivariate statistical techniques for the evaluation of spatial and temporal variations in water quality of Gomti River (India), a case study. Water Research, 38, 3980-3992. 